\title{
A EMENDA CONSTITUCIONAL № 95/2016 E A VIOLAÇÃO DA IDEOLOGIA CONSTITUCIONALMENTE ADOTADA
}

\author{
UMBERTO ABREU NOCE ${ }^{\dagger}$ \\ GIOVANI CLARK ${ }^{\dagger \dagger}$
}

RESUMO: O trabalho tem como objetivo analisar a (in)constitucionalidade da Emenda Constitucional ${ }^{\circ}$ 95/2016, limitadora dos investimentos públicos da União por 20 (vinte) anos, fixando o teto de aumento das despesas primárias em percentual, conforme a variação dos índices inflacionários verificados no ano anterior. A pesquisa é eminentemente documental, tendo como referencial teórico o conceito de ideologia constitucionalmente adotada, desenvolvido pelo Professor Washington Peluso Albino de Souza, introdutor do Direito Econômico no Brasil, assim como o seu método de investigação científica, ou seja, Analítico Substancial.

PalaVRAS-ChAVE: Emenda Constitucional n 95/2016; Ideologia Constitucionalmente Adotada; Planejamento; Despesas Primárias; Anarcocapitalismo.

\footnotetext{
† Advogado e Mestrando em Direito Público no Programa de Pós Graduação da Pontifícia Universidade Católica de Minas Gerais (PUC-Minas).

${ }^{\dagger}$ Doutor, Mestre e Bacharel em Direito pela Universidade Federal de Minas Gerais (UFMG) e Professor da Pontifícia Universidade Católica de Minas Gerais (PUCMinas), nos cursos de Graduação, Mestrado e Doutorado, e da Faculdade de Direito da UFMG, no curso de Graduação.
} 
ABstract: The purpose of this article is to analyze the (un)constitutionality of the Constitutional Amendment No. 95/2016, which limits public investment by the Federal Administration for 20 years, setting the ceiling for primary expenditures rise in percentage terms, as per variation of inflation indexes verified in the previous year. The search is eminently documentary, and its main theoretical reference is the concept of constitutionally adopted ideology, conceived by Prof. Washington Peluso Albino de Souza, who introduced the Economic Law in Brazil, as well as his scientific investigation methodology (i.e., Analytical Substantial).

KEYWORDS: Constitutional Amendment No. 95/2016; Constitutionally Adopted Ideology; Planning; Primary Expenditures; AnarchoCapitalism. 


\section{SUMÁRIO:}

I. INTRODUÇ̃̃o

II. NOÇÕES SOBRE PLANEJAMENTO

III. ORÇAMENTO PÚBLICO E SUA RELAÇÃO COM O PLANEJAMENTO.1222

IV. A DISTINÇÃO ENTRE DESENVOLVIMENTO

E CRESCIMENTO ECONÔMICO

V. O CONTEÚDO DA EMENDA CONSTITUCIONAL No 95/2016..............1227

1. Problema democrático: cria cláusula pétrea indireta e suspende as prerrogativas democráticas

2. Inviabilização dos direitos sociais da Constituição e do princípio da vedação do retrocesso.

VI. NAS TRILHAS DO ANARCOCAPITALISMO..........................................1236

VII. CONSIDERAÇÕES FINAIS ...........................................................1239

VIII.REFERÊNCIAS ...................................................................................1241

\section{TABLE OF CONTENTS:}

I. INTRODUCTION ................................................................................1219

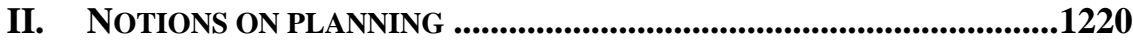

III. PUBLIC BUDGET AND ITS RELATION TO PLANNING ..........................1222

IV. THE DISTINCTION BETWEEN DEVELOPMENT AND ECONOMIC GROWTH ................................................................1225

V. THE CONSTITUTIONAL AMENDMENT No. 95/2016 CONTENT .......1227

1. Democratic problem: creates indirects entrenchment clauses and suspends democratic prerogatives..................1228

2. Inviabilization of constitutional social rights and the non-retrocess principle ........................................1232

VI. ON THE TRACKS OF ANARCHO-CAPITALISM................................1236

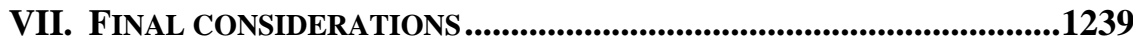

VIII.REFERENCES ..............................................................................................1241 


\section{INTRODUÇÃo}

Inserido em um contexto de grave crise econômica, fiscal e política, o Estado brasileiro necessita encontrar saídas para o quadro atual de depressão de receitas e, ao mesmo tempo, aprofundar o debate sobre o papel dos poderes públicos no domínio socioeconômico. Diante disso, o recente Governo Federal apresentou e aprovou uma Emenda (n ${ }^{\circ}$ 95/2016) à Constituição que estabelece, pelo prazo de vinte exercícios financeiros, $\mathrm{o}$ teto de aumento das despesas primárias em percentual, conforme a variação dos índices inflacionários verificados no ano anterior.

Festejada pela grande imprensa e pelos neoliberais reguladores, a Emenda Constitucional $n^{\circ}$ 95/2016 encontrou forte resistência no tecido social, ou seja, de diversas instituições, movimentos organizados e entidades prestadoras de serviços públicos e privados, muito embora tenha sido aprovada com relativa "tranquilidade". Focada unicamente na contenção das despesas primárias, como receituário para correção do quadro fiscal, a proposta (agora Emenda) avançou com presteza junto ao Poder Constituinte Derivado, sem efetivo aprofundamento no debate democrático acerca da medida tão polêmica e cujos efeitos se prolongarão por período considerável.

Desse modo, tem o presente artigo o objetivo de realizar uma análise sobre as questões jurídicas, sociais e econômicas da alteração constitucional, com claro destaque à pertinência constitucional ou não da referida Emenda, verificando sua compatibilidade com a Constituição brasileira de 1988 e sua ideologia adotada.

Iniciaremos o trabalho apresentando o instituto do planejamento, seu caráter técnico-político e sua correlação com o orçamento público. Em seguida, apresentaremos a distinção entre desenvolvimento e crescimento econômico da nação, haja vista a manifesta preocupação da Emenda com este último. Após, exploraremos, em termos gerais, o conteúdo da Emenda Constitucional n ${ }^{\circ}$ 95/2016, explicando suas medidas e seus efeitos. Ao final, apresentaremos nosso entendimento no que se refere à (in)constitucionalidade da Emenda estudada, analisando sua compatibilidade ou não com o texto constitucional brasileiro.

$\mathrm{O}$ método de pesquisa desenvolvido no presente trabalho foi eminentemente documental, tendo como referencial teórico a doutrina do ilustre professor e introdutor do Direito Econômico no Brasil, Washington Peluso Albino de Souza, notadamente sua abordagem sobre a Ideologia Constitucionalmente Adotada, como também o método Analítico Substancial de interpretação do Direito Econômico. 


\section{NOÇÕES SOBRE PLANEJAMENTO}

Estabelecido na Constituição de 1988, o instituto do planejamento estatal, muito embora ainda se verifiquem resistências, superou as desconfianças ao mesmo na atualidade, inclusive nas nações cujo sistema econômico se caracteriza por "menor intervenção" estatal no domínio econômico. Conforme advertiu o professor Washington Peluso Albino de Souza, incluindo os cenários de maior negação ao planejamento estatal, aquele não pode ser evitado em razão de que "o governo figura como o grande cliente da empresa privada, com os gastos na compra dos seus produtos e dos seus serviços" ${ }^{11}$, de sorte que não há de se falar em capitalismo produtivo atual sem a existência do planejamento e do Estado.

Assim, diante da incapacidade do "mercado" em atender a todas as demandas necessárias ao desenvolvimento ou ao crescimento econômico modernizante $^{2}$, é necessária a atuação estatal planejada como instrumento de equilíbrio entre oferta e demanda, a fim de garantir a produção, circulação, repartição e o consumo privado, bem como para estabelecer balizas da atividade econômica ${ }^{3}$, promover a justiça social, entre outras tantas missões descritas no texto constitucional, especialmente no artigo $3^{\circ}$ que traça os objetivos da nossa República, quais sejam, de construir uma sociedade livre, justa e solidária, garantir o desenvolvimento nacional, erradicar a pobreza e a marginalização e reduzir as desigualdades sociais e regionais e promover o bem de todos sem preconceitos de origem, raça, sexo, cor, idade e quaisquer outras formas de discriminação.

Desse modo, o planejamento se estabeleceu como essencial ao funcionamento do Estado, não apenas em relação à condução da economia, mas a toda atividade estatal e ao desempenho da máquina

1 SOUZA, Washington Peluso Albino de. Direito Econômico. São Paulo, SP: Saraiva, 1980, p. 451.

${ }^{2}$ Cf. BERCOVICI, Gilberto. Constituição Econômica e Desenvolvimento: uma leitura a partir da Constituição de 1988. São Paulo, SP: Malheiros, 2005.

${ }^{3}$ Cf. BRESSER-PEREIRA, Luiz Carlos; OREIRO, José Luis; MARCONI, Nelson.

Macroeconomia Desenvolvimentista: Teoria e Política Econômica do Novo

Desenvolvimentismo. Rio de Janeiro, RJ: Elsevier, 2016.

3 JOURNAL OF INSTITUTIONAL STUDIES 2 (2017) 
pública. Gilberto Bercovici ensina que o planejamento se divide em três fases ${ }^{4}$, quais sejam:

a) a decisão de planejar (fase política);

b) a implementação do planejamento (fase político-administrativa);

c) e o plano em si (aspecto técnico).

Destacando o caráter estruturante das políticas de Estado, através do planejamento, Giberto Bercovici ensina ainda que aquele se diferencia da mera intervenção casuística ou conjuntural, mas visa atender aos comandos decorrentes de uma política socioeconômica global ou parcial para atingir as finalidades sociais e constitucionais. ${ }^{5}$ Neste sentido, é majoritário entre os doutrinadores de Direito Econômico ao enquadrar o planejamento como uma intervenção indireta do Estado no domínio econômico, visando atender aos ditames constitucionais de transformações socioeconômicas, ambientais e tecnológicas. ${ }^{6}$ Embora discorde de tal enquadramento, Eros Grau não descarta o caráter político do planejamento, definindo-o como a racionalização da intervenção e não a intervenção em si. ${ }^{7}$

Sabe-se que, em um Estado Democrático de Direito, a "liberdade política" do Estado em relação às políticas econômicas deve encontrar balizas nas normas constitucionais, consistindo sua autonomia nas escolhas dos meios (quando possível) pelos quais se cumprirá o previsto no ordenamento jurídico, sobretudo no texto constitucional. Assim, devese, na atividade de planejamento, verificar quais os comandos

${ }^{4}$ Cf. BERCOVICI, Gilberto. Constituição Econômica e Desenvolvimento: uma leitura a partir da Constituição de 1988. São Paulo, SP: Malheiros, 2005.

${ }^{5}$ Cf. BERCOVICI, Gilberto. Constituição Econômica e Desenvolvimento: uma leitura a partir da Constituição de 1988. São Paulo, SP: Malheiros, 2005.

${ }^{6}$ Cf. SOUZA, Washington Peluso Albino de. Primeiras Linhas de Direito Econômico. $6^{\underline{a}}$ ed. $2^{\underline{a}}$ tiragem. São Paulo, SP: LTr, 2017; CLARK, Giovani; CORRÊA, Leonardo Alves; NASCIMENTO, Samuel Pontes do. Ideologia Constitucional e Pluralismo Produtivo. Revista da Faculdade de Direito da Universidade Federal de Minas Gerais, Número Especial: em memória do Professor Washington Peluso Albino de Souza, 2013; e CAMARGO, Ricardo Antonio Lucas. Curso Elementar de Direito Econômico. Porte Alegre, RS: Núria Fabris Editora, 2014.

${ }^{7}$ Cf. GRAU, Eros Roberto. A Ordem Econômica na Constituição de 1988: interpretação e crítica. 15a ed. São Paulo, SP: Malheiros, 2012. 
constitucionais a sociedade definiu como legítimos e conformadores das políticas econômicas, bem como a ideologia constitucionalmente adotada. ${ }^{8}$

Assim sendo, faz-se necessária, ainda, uma análise da definição da ideologia constitucionalmente adotada, que, nas palavras de Washington Peluso Albino de Souza, "é o conjunto de princípios relacionados com a vida econômica e tratados harmonicamente pelo Direito. Como Direito Positivo, são os princípios inseridos na Constituição" ${ }^{9}$. Verificado qual o ideário constitucionalmente adotado a partir dos comandos da Constituição de 1988, cabe ao planejamento (via legislação planejadora) materializá-los na realidade socioeconômica nacional.

Portanto, diante da obrigatória observância aos ditames constitucionais, objetiva-se, na pesquisa, analisar se a Emenda Constitucional $n^{\circ}$ 95/2016, inserida nos Atos das disposições constitucionais transitórias, atende à ideologia constitucionalmente adotada e, por consequência, garante os compromissos sociais insculpidos em seu texto.

\section{ORÇAMENTO PÚBLICO E SUA RELAÇÃO COM O PLANEJAMENTO}

A partir de um conceito estritamente técnico, o orçamento público consiste em realizar previsão de receitas e fixação de despesas definidas a um determinado Estado, no caso específico brasileiro, pelo período de um ano (art. 165, §8으. CR/88). No entanto, o orçamento é, na verdade, a face concreta do planejamento estatal, ou seja, a consubstanciação em um documento (definição de receitas e gastos financeiros) de uma opção política e jurídica adotada pelo Estado.

Com clareza, Régis Fernandes de Oliveira define orçamento público como:

${ }^{8}$ Cf. SOUZA, Washington Peluso Albino de. Primeiras Linhas de Direito Econômico. 6ª ed. 2a tiragem. São Paulo, SP: LTr, 2017.

9 SOUZA, Washington Peluso Albino de. Direito Econômico. São Paulo, SP: Saraiva, 1980, p. 34.

3 JOURNAL OF INSTITUTIONAL STUDIES 2 (2017) 
Lei em sentido formal, que estabelece a previsão de receitas e despesas, consolidando posição ideológica governamental, que lhe imprime caráter programático. Ao lado de ser lei, é o orçamento um plano de governo, mas que deve possuir previsões efetivas de ingressos públicos e previsões reais de despesas, equilibradas com aqueles. ${ }^{10}$

Com efeito, reafirmando o condicionamento estabelecido do orçamento ao planejamento, Maria Berenice Rosa ensina que o planejamento fixado pela lei do plano plurianual estabelece, por sua vez, as balizas da lei de diretrizes orçamentárias que, por fim, ditam o conteúdo do orçamento público. ${ }^{11}$ Ademais, alertamos que a legislação planejadora não se restringe às ditas leis, há diversas outras previstas no mesmo texto constitucional como pode-se destacar os artigos 182 e 187 $\mathrm{CR} / 88$.

Dado o seu caráter político-jurídico, o orçamento público não pode como comumente divulgado pelos meios de comunicação de massa - ser confundido com o orçamento doméstico, pois neste ambiente uma despesa realizada não possui, salvo raras exceções, a possibilidade de retorno como receita.

Por outro lado, a despesa pública, mesmo quando aparenta ser um custo sem possibilidade direta de regresso ao erário, "indiretamente" poderá implicar este efeito. É o exemplo dado pelo jornalista Bernardo Kucinski acerca da política de valorização do salário mínimo, apontando que ele significa incremento na renda das pessoas possuindo forte possibilidade de retornar aos cofres públicos pela via dos tributos, uma vez considerada a prática do consumo de bens e serviços no mercado sobretudo em razão da baixa ocorrência de realização de poupança entre os que auferem menores salários. ${ }^{12}$ Assim mais salários aos trabalhadores e proventos aos servidores públicos gerarão aumento do consumo e da produção, e consequentemente significará aumento da arrecadação tributária e redução com alguns gastos públicos (segurança, seguro

${ }^{10}$ OLIVEIRA, Régis Fernandes de. Curso de Direito Financeiro. $6^{\underline{a}}$ ed. São Paulo, SP: Revista dos Tribunais, 2014, p. 575.

${ }^{11}$ Cf. ROSA, Maria Berenice. Contabilidade do Setor Público. São Paulo, SP: Atlas, 2011.

${ }^{12}$ KUCINSKI, Bernardo. Cartas a Lula: o jornal particular do presidente e sua influência no governo do Brasil. Rio de Janeiro, RJ: Edições de Janeiro, 2014.

3 JOURNAL OF INSTITUTIONAL STUDIES 2 (2017) 
desemprego, exemplificando).

Ademais, a decisão de quando e onde gastar é eminentemente política ${ }^{13}$, bem como jurídica constitucional. É no momento da confecção do orçamento que deveriam ocorrer os mais acirrados debates políticos, sendo confrontados e discutidos os interesses de todos os segmentos sociais.

Dada a natureza jurídica e política do orçamento, faz-se necessário o debate democrático quando da definição de qual será a alocação dos investimentos públicos ${ }^{14}$, fixando gastos e prevendo receitas, sob pena de a peça orçamentária assumir um caráter autoritário. Não é por outra razão que o orçamento municipal (por exemplo), obrigatoriamente, deve passar por um percurso democrático, conforme estabelece o art. 44 do Estatuto das Cidades (Lei no $10.257 / 2001$ ).

Por todo o exposto, uma vez aprovada a Emenda Constitucional $\mathrm{n}^{\circ}$ 95/2016, que estabelece um teto rigoroso para as despesas públicas primárias, "retirará" da pauta estatal a questão acerca da provisão de receitas, como alertou a economista Laura Carvalho, em debate realizado recentemente na FEA-USP. ${ }^{15}$ Assim, nos cabe questionar se não restaria suprimido o caráter eminentemente democrático do orçamento público, bem como se não estariam inviabilizados os compromissos sociais constitucionalmente adotados.

${ }^{13}$ Cf. OLIVEIRA, Régis Fernandes de. Curso de Direito Financeiro. $6^{\mathrm{a}}$ ed. São Paulo, SP: Revista dos Tribunais, 2014.

${ }^{14}$ Cf. CLARK, Giovani. O Município em face do Direito Econômico. Belo Horizonte, MG: Del Rey, 2001.

${ }^{15}$ Debate realizado entre as congressistas Dra Laura Carvalho e a economista Mônica de Bolle, no evento denominado Economia à Brasileira: Laura Carvalho e Monica de Bolle debatem: PEC 241 - Teto dos Gastos Públicos, realizado na Faculdade de Economia, Administração e Contabilidade da Universidade de São Paulo - USP, em 18 de outubro de 2016. A propósito, cf. CARVALHO, Laura. PEC 241 pode prolongar a crise. Folha de São Paulo, 13 de outubro de 2016. Disponível em: $<$ http://www1.folha.uol.com.br/colunas/laura-carvalho/2016/10/1822278-pec-241-podeprolongar-a-crise.shtml>. Acesso em: 27 de dezembro de 2017.

3 JOURNAL OF INSTITUTIONAL STUDIES 2 (2017) 


\section{A DISTINÇÃO ENTRE DESENVOLVIMENTO E CRESCIMENTO ECONÔMICO}

Quando enviada a proposta de Emenda Constitucional (PEC ${ }^{\circ}$ 55/2016), o então Ministro da Fazenda, Henrique de Campos Meirelles, acompanhado do Ministro do Planejamento, Dyogo Henrique de Oliveira, elaboraram razões formais a justificar os alegados benefícios da proposta de novo regime fiscal, assim como para defender a necessidade de sua aprovação. ${ }^{16}$ Depreende-se da leitura das razões apresentadas que a palavra crescimento - no sentido único de crescimento modernizante ${ }^{17}$ - é repetida por quatro vezes nas cinco páginas de texto.

Verifica-se, pois, a manifesta preocupação dos agentes públicos com o instituto de crescimento econômico e das eventuais consequências benéficas dele decorrentes, tais como: geração de empregos, expansão da receita pública, reaquecimento da economia, dentre outros. No entanto, há de se considerar, e, neste momento, já nos posicionando em relação à emenda pesquisada, a patente distinção entre crescimento e desenvolvimento, não considerada na referida justificativa, apesar de a Constituição brasileira prever expressamente a palavra "desenvolvimento" em várias partes de seu texto, tal como podemos encontrar no respectivo preâmbulo, no inciso II do artigo $3^{\circ}$, e artigos 182 e 219 .

Enquanto o crescimento é basicamente quantitativo e modernizante, a compreensão do desenvolvimento possui caráter prioritariamente qualitativo, devendo-se verificar outros aspectos além de eventual aumento das atividades econômicas. Nesse sentido, são também objetivos do desenvolvimento as melhorias nas condições sociais, o acesso a serviços públicos básicos e de qualidade, o respeito e o incremento dos direitos humanos, a preservação do meio ambiente, dentre uma série de outros elementos que atestam a elevação dos índices de desenvolvimento. ${ }^{18}$ Em síntese, como ensina o Professor Washington

\footnotetext{
${ }^{16}$ Disponível em:

$<$ http://www.camara.gov.br/proposicoesWeb/prop mostrarintegra?codteor=1468431\&f ilename=PEC241/2016 $>$. Acesso em: 27 de dezembro de 2017.

${ }_{17}$ Cf. BERCOVICI, Gilberto. Constituição Econômica e Desenvolvimento: uma leitura a partir da Constituição de 1988. São Paulo, SP: Malheiros, 2005.

${ }^{18}$ Cf. BERCOVICI, Gilberto. Constituição Econômica e Desenvolvimento: uma leitura a partir da Constituição de 1988. São Paulo, SP: Malheiros, 2005.
} 
Peluso Albino de Souza, "o planejamento é um desequilíbrio positivo". ${ }^{19}$ O economista Amartya Sen, um dos criadores do conceito de índice de desenvolvimento humano (IDH), atualmente adotado pelas Organizações das Nações Unidas (ONU), assim trata da questão:

O desenvolvimento dificilmente pode ser visto apenas com relação ao melhoramento de objetos inanimados de conveniência, como um aumento do PIB (ou da renda pessoal) ou a industrialização - apesar da importância que possam ter como meios para fins reais. Seu valor precisa depender do impacto que eles têm nas vidas e liberdades das pessoas envolvidas, que necessita ser central para a ideia de desenvolvimento..$^{20}$

No mesmo sentido, Jessé Souza alega a necessidade de se compreender o fenômeno do desenvolvimento não mais como mero crescimento econômico, mas sim como efetivo combate à miséria e às desigualdades presentes na nação, assim como nas formas pelas quais tratamos uns aos outros. ${ }^{21}$ Ademais, o crescimento econômico, quando não acompanhado da preservação ambiental (por exemplo), não é sustentável, limita-se, no máximo, a uma concepção de capitalismo produtivo, condenando todos a um futuro de destruição dos bens da natureza.

Todavia, a Emenda Constitucional n ${ }^{\circ}$ 95/2016 gerou objetivamente o congelamento dos investimentos estatais voltados para a educação, saúde, obras e segurança, priorizando o crescimento modernizante (sempre excludente), em detrimento do desenvolvimento, com a concepção de equilíbrio fiscal, a fim de atrair os investimentos privados, mas com sérios sacrifícios na prestação de serviços básicos à sociedade o que acarretará o descumprimento dos mais diversos comandos e compromissos constitucionais.

${ }^{19}$ SOUZA, Washington Peluso Albino de. Primeiras Linhas de Direito Econômico. $6^{\underline{a}}$ ed. $2^{a}$ tiragem. São Paulo, SP: LTr, 2017, p. 399.

${ }^{20}$ SEN, Amartya. A Ideia de Justiça. Trad. Denise Bottmann e Ricardo Doninelli Mendes. São Paulo, SP: Companhia das Letras, 2011, p. 380-381.

${ }^{21}$ Cf. SOUZA, Jessé. A Ralé Brasileira: quem é e como vive. Belo Horizonte, MG:

Editora UFMG, 2011.

3 JOURNAL OF INSTITUTIONAL STUDIES 2 (2017) 


\section{O CONTEÚDO DA EMENDA CONSTITUCIONAL № 95/2016}

Apresentadas as considerações acima, passaremos neste momento a tratar especificamente do conteúdo da Emenda Constitucional n 95/2016, que estabeleceu teto para as despesas primárias da União pelo prazo de até vinte exercícios financeiros. Com efeito, dado o caráter genérico do artigo, nos limitaremos às ideias centrais da emenda, sem adentrarmos em minúcias técnicas ou exceções que nos pareçam irrelevantes. Cumpre ressaltar que, dadas suas características de transitoriedade, a Emenda foi acrescida aos Atos das Disposições Constitucionais Transitórias.

Conforme se depreende do seu texto, a partir do exercício financeiro do ano de 2018, as despesas primárias da União voltadas para saúde, educação, obras, segurança, previdência, por exemplo, somente poderão ter aumento no mesmo percentual de variação verificado pelo Índice Nacional de Preços ao Consumidor Amplo (IPCA) do ano anterior.

Note-se que não se inclui na mesma limitação de aumento daqueles investimentos, o pagamento da dívida pública e seus juros, considerados como despesas financeiras.

O limite é imposto a todos os poderes da República em âmbito federal, bem como ao Ministério Público Federal, Defensoria Pública da União e Tribunal de Contas da União. Portanto, a Emenda Constitucional $\mathrm{n}^{\circ}$ 95/2016 fixa um planejamento impositivo a longo prazo de redução das despesas desse ente federativo.

Assim sendo, verbas destinadas à saúde manterão o mesmo percentual mínimo, até então constitucionalmente previsto, entretanto a correção/atualização também passará a ser realizada conforme variação do IPCA do ano anterior, e não mais sobre a receita, como nos moldes atuais.

De forma excepcional, não se submetem ao referido índice de correção monetária os valores repassados a título de transferências aos Estados e Municípios de forma geral; os créditos extraordinários previstos no art. 167, §3º̄ da Constituição da República; as despesas com a Justiça Eleitoral para realização de eleições e as despesas com aumentos de capitais das empresas estatais não dependentes, conforme art. 107, §6º da Emenda.

Em seguida são estabelecidas uma série de punições aos órgãos ou poderes atingidos pela medida (em caso de descumprimento) consistindo basicamente em: proibições de contratação de pessoal, reajustes salariais aos quadros funcionais, criação de despesas obrigatórias, realização de concursos públicos, entre outras sanções que, como o próprio caput do 
art. 109 da Emenda Constitucional n ${ }^{\circ}$ 95/2016 deixa claro, não se esgotam nas elencadas no referido dispositivo legal.

Por fim, dois pontos na alteração constitucional são de profunda relevância - e que serão objeto de maior destaque a seguir: o extenso prazo de duração do regime, vinte exercícios financeiros, com a possibilidade de alteração apenas após dez anos; e o estabelecimento da possibilidade de inibição ou suspensão de propostas de inovações legais ou/e constitucionais que impliquem aumento das despesas ou renúncia a receitas, a fim de "garantir/impor" o novo regime fiscal adotado pela Emenda Constitucional n ${ }^{\circ}$ 95/2016.

\section{Problema democrático: cria cláusula pétrea indireta e suspende prerrogativas democráticas}

Como destacou a economista Laura Carvalho, em debate já mencionado no artigo, não existe política econômica desvinculada de uma visão das Ciências Econômica e Política. ${ }^{22}$ Em outras palavras, não é verdadeira a intenção de apresentar uma decisão de política econômica como algo estritamente técnico, visto que, necessariamente se dependerá de uma escolha obviamente política.

Diante deste caráter político das decisões econômicas, justifica-se o tópico apresentado no artigo acerca do que se configura o planejamento estatal e o orçamento público. Como visto, ambos são instrumentos técnicos, mas validados em decisões de cunho eminentemente político, econômico e constitucional. Diante disso, é ilusória a tentativa de se apresentar como única e salvadora saída - e de caráter estritamente técnico - a Emenda ora pesquisada, estabelecedora de limites de despesas aos poderes e órgãos da União.

Com efeito, a Emenda Constitucional $n^{\circ}$ 95/2016, essencialmente política, além de não ser a única saída possível - dado que sequer cogitou a questão da receita - possui diversas atecnias maculadoras de sua constitucionalidade. Não por outra razão, a Consultoria Técnica do

${ }^{22}$ Cf. CARVALHO, Laura. PEC 241 pode prolongar a crise. Folha de São Paulo, 13 de outubro de 2016. Disponível em: <http://www1.folha.uol.com.br/colunas/lauracarvalho/2016/10/1822278-pec-241-pode-prolongar-a-crise.shtml>. Acesso em: 27 de dezembro de 2017.

3 JOURNAL OF INSTITUTIONAL STUDIES 2 (2017) 
Senado Federal emitiu parecer pela inconstitucionalidade da ainda Proposta de Emenda Constitucional (PEC n 55/2016), sob diversos argumentos, dentre os quais destacam-se: a) criação indireta de novas cláusulas pétreas e b) violação ao voto direto, secreto, universal e periódico. ${ }^{23}$

Assim, a emenda versada possui dois dispositivos que causam surpresa, haja vista o caráter autoritário de suas disposições, com a consequente supressão das prerrogativas democráticas conferidas aos representantes eleitos pela sociedade. Ao estabelecer que após dez anos de vigência do novo regime fiscal poderá o Presidente da República encaminhar lei complementar objetivando alterar o teto de despesas, a emenda, logo em seguida, limita a possibilidade de alteração a uma propositura legislativa por mandato.

Salta aos olhos, portanto, o enclausuramento expresso do exercício da função do chefe do Executivo, mesmo sendo democraticamente eleito, quanto à respectiva liberdade de atuação em relação ao orçamento, mesmo já ultrapassados mais de dez anos da edição da emenda em análise. É o conteúdo do parágrafo único do seu art. 108:

Art. 108. O Presidente da República poderá propor, a partir do décimo exercício da vigência do Novo Regime Fiscal, projeto de lei complementar para alteração do método de correção dos limites a que se refere o inciso II do $\S 1^{0}$ do art. 107 deste Ato das Disposições Constitucionais Transitórias.

Parágrafo único. Será admitida apenas uma alteração do método de correção dos limites por mandato presidencial.

Por sua vez, ao tratar das sanções impostas em razão do descumprimento dos limites de despesas estabelecidos pelo novo regime fiscal, o $\$ 4^{\circ}$, do art. 109, estabelece que "As vedações previstas neste artigo aplicam-se também a proposições legislativas."

${ }^{23}$ Cf. VIEIRA JUNIOR, Ronaldo Jorge Araujo. As Inconstitucionalidades do "Novo Regime Fiscal" Instituído pela PEC no 55, de 2016 (PEC no 241, de 2016, na Câmara dos Deputados). Boletim Legislativo do Núcleo de Estudos e Pesquisas da Consultoria Legislativa, No. 53, 2016. Disponível em:

$<\underline{\text { https://www12.senado.leg.br/publicacoes/estudos-legislativos/tipos-de- }}$ estudos/boletins-legislativos/bol53>. Acesso em: 27de dezembro de 2017.

3 JOURNAL OF INSTITUTIONAL STUDIES 2 (2017) 
O art. 114 da emenda estabelece, ainda, a possibilidade de suspensão da tramitação de alteração normativa cujo conteúdo acarrete aumento de despesa ou supressão de receitas, a fim de verificar sua consonância com o novo regime fiscal.

Sabe-se que as cláusulas pétreas são limitações estabelecidas no texto constitucional originário acerca de temas que, por consagrarem a ideologia constitucional, não podem ser objeto de deliberação por inovação jurídica quando objetive esvaziamento de seu conteúdo. ${ }^{24}$

Sendo assim, as previsões constitucionais limitadoras de simples discussão de normas em sentido contrário, são aquelas determinações víeis ao espírito da Constituição, e desse modo garantem a possibilidade de ser exercido controle prévio de constitucionalidade. Entretanto, o que o novo regime fiscal apresenta é a vedação da mera proposição de normas que a ele não se enquadrem, conforme $\S^{\circ}{ }^{\circ}$ do art. 109 destacado acima.

Ora, o estabelecido pelas inovações, de forma "transversa", é a proibição de deliberação legal ou constitucional que não se ajuste ao novo regime fiscal. Assim, de forma indireta, houve instauração de novas cláusulas pétreas, ou seja, vedam alterações legais e constitucionais em sentido contrário, mesmo a mera discussão e, portanto, em nada se diferencia a previsão contida no art. $109, \S 4^{\circ}$, da emenda ao apontar que não poderá ser apresentada qualquer proposta legislativa geradora de aumento de despesas. Ademais, o art. 114 possibilita a suspensão de proposições legais que não observem o novo regime fiscal.

Não bastasse as inconstitucionalidades apontadas acima, o órgão de consultoria do Senado verificou que a PEC n ${ }^{\circ}$ 55/2016 também implicava lesão ao direito de voto direto, universal, secreto e periódico. Isso porque, ao impor limitações orçamentárias por um período tão demasiado, estaria a suprimir as prerrogativas dos futuros presidentes eleitos em administrar com liberdade orçamentária e com isso exercer o mandato em sua plenitude, resultando assim em lesão ao direito de voto e obstruindo a escolha democrática do eleitor por outras políticas socioeconômicas.

Aderindo à compreensão exposta, não observa a Emenda Constitucional $n^{\circ} 95 / 2016$ a prerrogativa do efetivo exercício do debate constitucionalmente democrático garantido aos futuros representantes eleitos pela sociedade, ao impor a limitação, por vinte exercícios

${ }^{24}$ Cf. MENDES, Gilmar Ferreira; COELHO Inocêncio Mártires; BRANCO, Paulo Gustavo Gonet. Curso de Direito Constitucional. 5ª ed. São Paulo, SP: Saraiva, 2010. 
financeiros, do reajuste de despesas primárias do Estado.

Ora, na eventualidade de a nação retomar o crescimento modernizante ou trilhar os caminhos do desenvolvimento, auferindo maiores receitas, estaria vedada a retomada de investimentos estatais, em razão de limitação draconiana aos gastos públicos, quando não mais presente a questionável realidade que a impôs. Vê-se, pois, que não poderá a sociedade, mesmo verificado quadro fiscal distinto, reestabelecer o debate acerca da ampliação dos investimentos do orçamento, pelo engessamento estabelecido pela referida emenda constitucional.

Outrossim, mesmo após superados os dez anos mínimos de vigência do regime imposto pelo dispositivo legal ora analisado, cada Presidente da República somente poderá sugerir uma única alteração por mandato, como define o seu artigo 108, parágrafo único. Por sinal, limitação totalmente desproporcional e violadora dos ditames constitucional e de sua ideologia adotada.

Sem aprofundarmos no debate democrático e participativo (artigos $1^{\circ}$ e $14^{\circ}$ da CR/88), há, ainda, o agravante de que a emenda foi "imposta" por um governo não eleito ${ }^{25}$, carecendo assim tal limitação, tão gravosa às presentes e futuras gerações, da legitimidade do voto.

A partir de uma interpretação analógica poder-se-ia admitir, no máximo, que a duração para o novo regime fiscal se limitasse ao período de mandato do atual chefe do executivo, considerando-se, também, o primeiro ano do mandado posterior, tal como ocorre na experiência do plano plurianual (04 anos).

Embora se trate de contexto distinto e de forma indireta, o professor Washington Peluso Albino de Souza já alertava acerca da impossibilidade de imposição de restrições orçamentárias aos mandatos seguintes:

A Lei do Plano oferece como uma de suas peculiaridades a de ter duração predeterminada. Respeitado o princípio democrático de que um governo não

${ }^{25}$ Cumpre esclarecer que a Proposta de Emenda Constitucional ora discutida foi apresentada por uma composição de governo originada em razão de um processo de impedimento da presidente eleita pelo sufrágio popular e, com efeito, o sucessor do cargo presidencial - e anterior vice-presidente - adotou medidas manifestamente divorciadas do plano de governo que havia sido apresentado pela chapa vencedora das eleições presidenciais de 2014.

3 JOURNAL OF INSTITUTIONAL STUDIES 2 (2017) 
pode impor medidas administrativas ou político-econômicas ao seu sucessor, a Lei do Plano deve ser elaborada e sua vigência deve extinguir-se dentro do período de mandato de um governo. ${ }^{26}$

Portanto, a garantia de uma democracia participativa efetiva vai além do mero funcionamento formal das instituições. Depende da possibilidade de debate e decisões, ou seja, adotar as discussões amplas e deliberações coletivas como elementos básicos da democracia ${ }^{27}$, infelizmente suprimidos pela emenda estudada.

\section{Inviabilização dos direitos sociais da Constituição e princípio da vedação do retrocesso}

Em face do conteúdo da Emenda Constitucional n 95/2016, verificase que, mesmo "preservados" os investimentos em saúde e educação no ano de 2017, a partir do exercício subsequente a correção destas rubricas ocorrerá conforme variação do IPCA do ano anterior. Assim, o que se verificará é um verdadeiro contingenciamento dos gastos em direitos sociais, viabilizados por serviços públicos, para o significativo período de dezenove anos. Outrossim, dada a amplitude de despesas obrigatórias do Estado brasileiro, ficarão também sobremaneira afetados os recursos para os demais investimentos, sejam de caráter exclusivamente social ou não.

Em nota técnica divulgada, os pesquisadores do Instituto de Pesquisa Econômica Aplicada, Fabiola Vieira e Rodrigo Benevides, demonstraram que a consequência da ainda PEC $n^{\circ}$ 55/2016 seria uma considerável redução do gasto per capita, por exemplo, com saúde, visto que os estudos apontam pela tendência de crescimento e envelhecimento populacional nos anos seguintes. ${ }^{28}$ Idêntica situação se verificaria também no setor

${ }^{26}$ SOUZA, Washington Peluso Albino de. Direito Econômico. São Paulo, SP: Saraiva, 1980, p. 454.

${ }^{27}$ Cf. SEN, Amartya. A Ideia de Justiça. Trad. Denise Bottmann e Ricardo Doninelli Mendes. São Paulo, SP: Companhia das Letras, 2011.

${ }_{28}$ VIEIRA, Fabiola Sulpino; BENEVIDES, Rodrigo Pucci de Sá. Os Impactos do Novo Regime Fiscal para o Financiamento do Sistema Único de Saúde e para a Efetivação do Direito à Saúde no Brasil. Nota Técnica: IPEA, No. 28, 2016. Disponível em: 
educacional, bem como em outras áreas demandantes de prestações positivas do Estado.

O novo regime fiscal implica na ruptura do pacto social estabelecido pela Constituição de 1988 e, por consequência, afronta o princípio do não retrocesso social, ou seja, retroagirá, inviabilizará ou reduzirá conquistas socais civilizatórias (direitos), por intermédio de política econômica de víeis fiscal. Neste sentido, escreve Sarlet:

A problemática da proibição de retrocesso guarda íntima relação com a noção de segurança jurídica. (...) a idéia de segurança jurídica encontra-se umbilicalmente vinculada também à própria noção de dignidade da pessoa humana. Com efeito, a dignidade não restará suficientemente respeitada e protegida em todo o lugar onde as pessoas estejam sendo atingidas por um tal nível de instabilidade jurídica que não estejam mais em condições de, com um mínimo de segurança e tranqüilidade, confiar nas instituições sociais e estatais (incluindo o Direito) e numa certa estabilidade das suas próprias posições jurídicas. ${ }^{29}$

A Constituição Brasileira é pródiga em princípios que determinam prestações positivas do Estado, garantindo direitos sociais e individuais, possuindo como princípios a redução das desigualdades sociais e regionais, erradicação da pobreza, objetivando assegurar vida digna e uma sociedade justa. Assim sendo, normas jurídicas estabelecidas em sentido contrário rompem as determinações transformadoras ditadas pela nossa Lei Maior (materialização de direitos), inclusive também viola a ideologia constitucionalmente adotada, como assinala Washington Peluso Albino de Souza:

Não se trata do sentido filosófico ou político amplo, de ideologia, nem mesmo de cada ideologia política geralmente referida, tal como a capitalista, a

$<$ http://www.conass.org.br/wpcontent/uploads/2016/09/NOTA TECNICA IPEA241.pdf >. Acesso em: 27 de dezembro de 2017.

${ }^{29}$ SARLET, Ingo Wolfgang. A Eficácia dos Direitos Fundamentais. $8^{\mathrm{a}}$ ed. Porto Alegre, RS: Livraria do Advogado, 2007, p. 436-437.

3 JOURNAL OF INSTITUTIONAL STUDIES 2 (2017) 
socialista, a comunista, etc. Independentemente dessa configuração, referimo-nos aos princípios que sejam fundamentais na ordem jurídica considerada, mesmo que isoladamente se identifiquem com alguma daquelas ideologias políticas acima referidas. A ideologia a que nos referimos é aquela definida, em Direito Positivo, no Estado de Direito, pela Constituição vigente, em cada época e em cada país. Por isso, a definimos como "ideologia constitucionalmente adotada". Fica estabelecida, pois, a diferença entre esta e a que se possa entender por ideologia dos modelos teóricos tradicionais, ou seja, conjuntos de ideias, de princípios ou de teorias destinados a explicar, abstratamente, a organização social, a estrutura política e assim por diante. De modo geral, em se tratando da presença dos temas econômicos nas Constituições modernas, boa parte dos elementos considerados como correspondentes a esse conceito de ideologia estão reunidos no capítulo da "Ordem Econômica e Social", que por essa razão é denominado "Constituição Econômica", apesar de muitos deles também se encontrarem dispersos por outras partes do texto constitucional. ${ }^{30}$

Não se nega que restrições orçamentárias, sobretudo em períodos de crise, fazem revezes nos procedimentos de garantia de direitos constitucionais, em que pese jamais terem sido efetivamente proporcionados à significativa parte da população pelo Estado brasileiro por décadas. Entretanto, distinguem-se eventuais dificuldades de uma emenda que limita de forma drástica, por vinte exercícios financeiros, os investimentos do Estado, inclusive as necessidades mais vitais a uma sociedade.

Ao incluir somente as despesas primárias, no âmbito da limitação de reajuste, a Emenda Constitucional n ${ }^{\circ}$ 95/2016 opta por restringir os gastos sociais e manter inalteradas as despesas com o serviço da dívida pública, sendo tal rubrica a maior no orçamento e a que mais cresce em relação à receita da União. ${ }^{31}$ Direcionamento semelhante já havia sido adotado quando da edição da Lei de Responsabilidade Fiscal (Lei Complementar

${ }^{30}$ SOUZA, Washington Peluso Albino de. Primeiras Linhas de Direito Econômico. $6^{\text {a }}$ ed. $2^{\text {a }}$ tiragem. São Paulo, SP: LTr, 2017, p. 28-29.

${ }^{31}$ Como referência citamos trabalhos realizados pela organização Auditoria Cidadã.

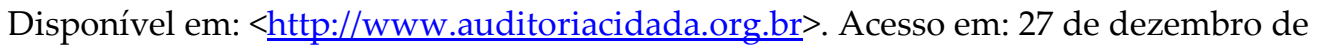
2017.

3 JOURNAL OF INSTITUTIONAL STUDIES 2 (2017) 
$\mathrm{n}^{\circ}$ 101/2000), em seu artigo 9o, $\$ 2$ o, ao tratar das hipóteses de contingenciamento de gastos, aponta não ser possível tal restrição em relação ao pagamento do serviço da dívida estatal.

Régis Fernandes de Oliveira defende a inconstitucionalidade ${ }^{32}$ da limitação contida na Lei de Responsabilidade Fiscal, e entendimento distinto não pode ser dispensado à Emenda Constitucional n ${ }^{\circ}$ 95/2016, limitadora das despesas primárias públicas, por vinte anos, entretanto silente acerca do pagamento da dívida e de seus juros. Tal opção não é condizente com os princípios e ditames constitucionais e implica grave retrocesso social, vedado claramente pela doutrina.

Assim sendo, não bastassem as inconstitucionalidades já apontadas, a reforma do teto de gastos refuta os compromissos sociais estabelecidos na Constituição de 1988 e gerará graves retrocessos na prestação de serviços sociais, investimentos públicos e garantias de direitos, não possibilitando outra interpretação possível senão a inconstitucionalidade da Emenda Constitucional n 95/2016, inclusive por violar a ideologia constitucional plural de nossa Lei Maior, inviabilizando assim os seus ditames de transformações socioeconômicas, ambientais e tecnológicas, assim como já anunciado por Giovani Clark, Leonardo Alves Corrêa e Samuel Pontes do Nascimento:

Em termos gerais, "ideologia constitucionalmente adotada" refere-se ao processo jurídico-político de conversão de "ideologias econômicas puras" (capitalismo, nacionalismo, socialismo) em uma ordem juridicamente positivada mesclando-as em um único texto a ser aplicado. Trata-se de um mecanismo de juridificação do discurso ideológico construído, no plano econômico-político, pelo Poder Constituinte. ${ }^{33}$

32 Por consequência, a opção feita pelo legislador do pagamento da dívida pública, em detrimento da consecução dos fins constitucionalmente estabelecidos, é

inconstitucional. Como pode haver alternativa ao legislador para escolha quando a Constituição estabeleceu vetores nos arts. $1^{\circ}$ e $3^{\circ}$, bem como outros esparsos, todos destinados a amparar o ser humano em sua essência. Cf. OLIVEIRA, Régis Fernandes de. Curso de Direito Financeiro. $6^{\mathrm{a}}$ ed. São Paulo, SP: Revista dos Tribunais, 2014, p. 448.

${ }^{33}$ CLARK, Giovani; CORRÊA, Leonardo Alves; NASCIMENTO, Samuel Pontes do. Ideologia Constitucional e Pluralismo Produtivo. Revista da Faculdade de Direito da

3 JOURNAL OF INSTITUTIONAL STUDIES 2 (2017) 


\section{NAS TRILHAS DO ANARCOCAPITALISMO}

Diversos estudiosos do Direito Econômico compreendem que, com as emendas constitucionais realizadas no Brasil durante a década de 1990, implementaram-se na nação, de forma planejada, a transição de um modelo neoliberal de regulamentação para um neoliberalismo de regulação. ${ }^{34}$ Ainda que haja discordância quanto aos termos ou amplitude das "reformas", é consenso que o objetivo central das Emendas dos anos noventa era reduzir o "tamanho do Estado" e sua participação direta no domínio econômico. Na realidade, o Estado remodelou a sua intervenção, a fim de abrir mais espaços e garantir liberdades ao setor privado lucrativo, fragilizando o seu papel e os deveres constitucionais dos poderes públicos.

Sem a intenção de aprofundamento sobre Emendas Constitucionais adotadas há mais de uma década, é certo que, após um período de forte a moderada intervenção estatal no domínio econômico, verificou-se a partir dos anos noventa uma tendência de "afastamento" do Estado no processo produtivo, ampliando-se a iniciativa privada e aprofundando a desregulamentação. Com efeito, apesar de observada uma leve retração deste movimento nos últimos três governos brasileiros eleitos (início do século XXI) - com a adoção de uma espécie de neodesenvolvimentismo de regulação - a estrutura que havia reduzido a atuação estatal não foi abandonada, quando não reforçada.

Laura Carvalho afirma que o objetivo central da proposta de Emenda Constitucional (hoje aprovada), estabelecendo limites de despesas

Universidade Federal de Minas Gerais, Número Especial: em memória do Professor Washington Peluso Albino de Souza, 2013, p. 276.

${ }^{34}$ Cf. SOUZA, Washington Peluso Albino de. Primeiras Linhas de Direito Econômico. $6^{\text {a }}$ ed. 2 ${ }^{\underline{a}}$ tiragem. São Paulo, SP: LTr, 2017; CLARK, Giovani. Política Econômica e Estado. In: Marcelo Campos Galuppo (Org.). O Brasil que queremos: Reflexões sobre o Estado Democrático de Direito. Belo Horizonte, MG: Editora PUC Minas, 2006; e CAMARGO, Ricardo Antonio Lucas. Curso Elementar de Direito Econômico. Porte Alegre, RS: Núria Fabris Editora, 2014.

3 JOURNAL OF INSTITUTIONAL STUDIES 2 (2017) 
primárias, era de realizar desmonte do Estado de Bem-Estar Social brasileiro. ${ }^{35}$ Mesmo que discordemos em termos, uma vez que, no nosso entender, o dito tipo de Estado não pode ser realmente desmontado, porque estava em construção inicial no Brasil. Todavia, ela acerta quanto ao objetivo da Emenda estudada, ou seja, é a redução profunda do "tamanho do Estado", ou remodelamento do seu papel.

Ao congelar por vinte anos os gastos públicos em serviços, investimentos, programas sociais, reajustes de servidores, entre outras limitações, será inevitável verificar o nosso afastamento, ainda mais relevante, dos compromissos sociais estabelecidos no texto original da Constituição da República do Brasil. É patente, portanto, que a Emenda Constitucional $n^{\circ}$ 95/2016 aprofunda um processo iniciado nas reformas da Administração Pública ocorridas nos anos noventa, do século passado, em que se adotou o modelo neoliberal de regulação, para então aplicar, conforme as regras da emenda ora estuda, os ditames do neoliberalismo de austeridade. O jurista lusitano António José Avelãs Nunes ensina sobre o recente papel do Estado com a sua "máscara" de garantidor e voltado à austeridade, sem contudo, referir-se ao anarcocapitalismo.

a) Ele é, frequentemente, "um conceito descritivo das transformações do estado": o estado garantidor afasta a responsabilidade de produzir determinados serviços públicos e de prosseguir ativamente determinadas tarefas estaduais, pretendendo "assumir apenas a responsabilidade pelo cumprimento das mesmas através de outras estruturas, a maior parte das vezes privadas", correndo o risco de se transformar em uma "terra de ninguém jurídica", sem um recorte rigoroso da sua dimensão normativa (não se sabe muito bem qual a responsabilidade deste estado garantidor, nem o que ele garante). b) Este estado garantidor tem alma de "estado social" e corpo de empresa (ou ao contrário: tem corpo de 'estado social' e alma de empresa): "pretende ainda garantir a socialidade, ou seja, os serviços sociais essenciais desde a saúde, as telecomunicações, energia, transportes, água - mas confia a serviços privados ou de gestão privada a prossecução directa desses

${ }^{35}$ Cf. CARVALHO, Laura. PEC 241 pode prolongar a crise. Folha de São Paulo, 13 de outubro de 2016. Disponível em: <http://www1.folha.uol.com.br/colunas/lauracarvalho/2016/10/1822278-pec-241-pode-prolongar-a-crise.shtml>. Acesso em: 27 de dezembro de 2017.

3 JOURNAL OF INSTITUTIONAL STUDIES 2 (2017) 
serviços". ${ }^{36}$

Por outro lado, cumpre apresentarmos o seguinte questionamento: o pretendido com o novo regime fiscal não seria a adoção de um modelo próximo ao anarcocapitalista, onde o Estado é suprimido de suas funções e atuações em todas as áreas, sendo substituído pelo "mercado" inclusive nos serviços públicos básicos? Ainda que pareça exagerada tal afirmação, foram concedidas pelo atual Ministro da Saúde diversas entrevistas e ele alegou ser impossível a manutenção de um sistema único de saúde nos moldes atuais, assim como defendeu-se a possibilidade de estabelecimento de "plano de saúde privado popular", em substituição ou em concorrência ao sistema de saúde pública. ${ }^{37}$

Luis Felipe Miguel, em artigo tratando de visões consideradas como alternativas utópicas à atual sociedade capitalista, relembra do anarcocapitalismo como possuidor de um ideário ultraliberal, objetivando a eliminação total do Estado e sua substituição pelo "mercado" (oligopolizado há décadas). ${ }^{38}$ Tal teoria advoga que a substituição completa do Estado pelas empresas garantiria maior eficiência e melhores serviços à sociedade, por ser a "concorrência" um claro motor de propulsão de qualidade.

Ademais, os anarcocapitalistas, renegam qualquer possibilidade de atuação estatal, porque entendem que limita as liberdades individuais e, defendem ainda a inviolabilidade da propriedade privada de produção e de consumo, afastando qualquer possibilidade de sua limitação pelos poderes públicos. Do mesmo modo, Luis Felipe Miguel destaca as dificuldades da teoria em relação à democracia, pois entende que ela seria imposta a todos, mesmo aos que dela discordem, pois reduz as

${ }^{36}$ AVELÃS NUNES, António José. As duas últimas máscaras do estado capitalista.

Pensar: Revista de Ciências Jurídicas, Vol. 16, 2, 2011, p. 443-444.

${ }^{37}$ Cf. LENHARO, Mariana. Proposta de "plano de saúde popular" inclui modalidade

sem internação nem urgência. G1, 08 de março de 2017. Disponível em:

$<$ http://g1.globo.com/bemestar/noticia/proposta-de-plano-de-saude-popular-incluimodalidade-sem-internacao-nem-urgencia.ghtml>. Acesso em: 27 de dezembro de 2017.

${ }^{38}$ Cf. MIGUEL, Luis Felipe. Utopias do Pós-Socialismo: Esboços e Projetos de Reorganização Radical da Sociedade. Revista Brasileira de Ciências Sociais, Vol. 21, 61, 2006. 
liberdades, e não se mostraria como o modelo mais eficiente de alocação de recursos:

Um subtexto importante do argumento dos anarcocapitalistas, assim como de outros ultraliberais, é a denúncia da democracia. Sua inferioridade como forma de alocação de recursos é ressaltada com freqüência, com auxílio de uma literatura próxima, que assinala a irracionalidade inerente aos processos de decisão pelo voto (Riker, 1982). As decisões democráticas ferem o dogma da liberdade individual, pois são impostas a todos, mesmo aos que discordam delas, e tendem a ser irresponsáveis, na medida em que o voto é um recurso sem custos para quem o usa. ${ }^{39}$

Verificadas as características da Emenda Constitucional n 95/2016, parece-nos que a visão de utopia - e, portanto, afastada da realidade apresentada por Luis Felipe Miguel não se mostra tão distante assim, e o congelamento por vinte anos dos investimentos públicos pode ser um caminho irreversível na implantação paulatina e planejada do anarcocapitalismo, assim como para a supressão do debate democrático e da inviabilização do Texto Constitucional brasileiro. ${ }^{40}$

\section{CONSIDERAÇÕES FINAIS}

Serão "reduzidas" as considerações finais do artigo, uma vez que expusemos em seu decorrer, de forma enfática, nosso entendimento acerca das inconstitucionalidades verificadas na Emenda Constitucional $n^{\circ}$ 95/2016. Dessa maneira, a questão que se impõe no momento é finalizar quanto às opções possíveis para o "problema fiscal" brasileiro e o caminho adotado pela medida única de contingenciamento de

${ }^{39}$ MIGUEL, Luis Felipe. Utopias do Pós-Socialismo: Esboços e Projetos de Reorganização Radical da Sociedade. Revista Brasileira de Ciências Sociais, Vol. 21, 61, 2006, p. 97.

${ }^{40}$ Cf. MIGUEL, Luis Felipe. Utopias do Pós-Socialismo: Esboços e Projetos de Reorganização Radical da Sociedade. Revista Brasileira de Ciências Sociais, Vol. 21, 61, 2006. 
investimentos.

A crise econômica (nacional e internacional) e o desaquecimento do processo produtivo capitalista impuseram considerável redução de receitas ao Estado brasileiro. Enquanto as despesas se mantiveram crescentes nas últimas décadas, a receita suportou enorme decréscimo quando iniciada a crise econômica atual. Isso se misturou à instabilidade política e foi dilatado, ainda, pelas desonerações fiscais sem o devido planejamento, além de subsídios (questionáveis) a setores, independentemente das necessárias contrapartidas, entre outras condutas que ampliaram a suposta debilidade da saúde fiscal do Brasil. Contudo, tal "debilidade" deve ser estudada e debatida profundamente no tecido social e não restringida a uma única interpretação governamental e empresarial.

A Emenda Constitucional $n^{\circ} 95 / 2016$ foi apresentada pela equipe econômica atual da União como a única medida possível para saneamento das contas públicas e consequente retomada do crescimento modernizante, mas não do desenvolvimento.

Na ocasião de proposta da referida emenda, observa-se, como forma de convencimento social, a implantação do discurso de que sua aprovação inclusive evitaria o surgimento de novos tributos para a sociedade.

Espantoso é que, em um sistema tributário nacional reconhecidamente injusto, pois efetivamente não alcança a capacidade contributiva de todos, considerando que tributa o consumo privilegiando os detentores de renda, patrimônio e herança, e diante do presente contexto econômico de dificuldades, a questão das receitas sequer se insere como objeto de debate ou, ainda mais grave, é apresentada sob a forma de um discurso que nitidamente intimida e ameaça a sociedade brasileira.

Ora, em uma nação onde não se verifica um imposto de renda efetivamente progressivo ${ }^{41}$; possuidor de um imposto sobre a herança reduzido, como se verifica nas mais diversas leis estaduais sobre tema, quando comparado com as experiências internacionais; não tributa,

${ }^{41}$ Vide tabela disponível em: <http://idg.receita.fazenda.gov.br/acessorapido/tributos/irpf-imposto-de-renda-pessoa-fisica>. Acesso em: 27 de dezembro de 2017.

3 JOURNAL OF INSTITUTIONAL STUDIES 2 (2017) 
ainda, a distribuição de lucros e dividendos;42 jamais legislou acerca do previsto imposto sobre grandes fortunas (art.153, VII, CR); e, finalizando, é pródigo em conceder benefícios fiscais a grandes grupos econômicos; não nos parece aceitável que o tema das receitas não possa fazer parte da essencialidade dos debates e decisões. Do mesmo modo, não se verifica planejamento efetivo no combate à sonegação de tributos.

Ademais, não podemos nós limitar a uma visão maniqueísta, digamos, na discussão entre Estado perdulário e Estado responsável, mas sim na defesa do cumprimento dos ditames sociais e transformadores de nossa Lei Maior, afetados pela inconstitucionalidade da Emenda Constitucional n ${ }^{\circ}$ 95/2016.

O contingenciamento de despesas resultará no sucateamento da máquina pública, de seus serviços e na inviabilização de direitos individuais e sociais, sem qualquer discussão quanto às receitas originárias e derivadas estatais, bem do dever constitucional daqueles que possuem mais condições de contribuir e não contribuem (art. 145, §1으, CR), ferindo, assim, texto constitucional e sua ideologia constitucionalmente adotada e colocando o Brasil de forma planejada nas trilhas do anarcocapitalsimo.

\section{REFERÊNCIAS}

AVELÃS NUNES, António José. As duas últimas máscaras do estado capitalista. Pensar: Revista de Ciências Jurídicas, Vol. 16, 2, 2011.

BRESSER-PEREIRA, Luiz Carlos; OREIRO, José Luis; MARCONI, Nelson. Macroeconomia Desenvolvimentista: Teoria e Política Econômica do Novo Desenvolvimentismo. Rio de Janeiro, RJ: Elsevier, 2016.

${ }^{42} \mathrm{Cf}$. VILAR, Isabela. Imposto sobre lucros e dividendos geraria $\mathrm{R} \$ 43$ bi ao ano, diz estudo. Senado Notícias, 14 de setembro de 2015. Disponível em:

$<$ http://www12.senado.leg.br/noticias/materias/2015/09/14/imposto-sobre-lucros-edividendos-geraria-r-43-bi-ao-ano-diz-estudo $>$. Acesso em: 27 de dezembro de 2017.

3 JOURNAL OF INSTITUTIONAL STUDIES 2 (2017) 
BERCOVICI, Gilberto. Constituição Econômica e Desenvolvimento: uma leitura a partir da Constituição de 1988. São Paulo, SP: Malheiros, 2005.

CAMARGO, Ricardo Antonio Lucas. Curso Elementar de Direito Econômico. Porte Alegre, RS: Núria Fabris Editora, 2014.

CARVALHO, Laura. PEC 241 pode prolongar a crise. Folha de São Paulo, 13 de outubro de 2016. Disponível em:

$<$ http://www1.folha.uol.com.br/colunas/laura-carvalho/2016/10/1822278pec-241-pode-prolongar-a-crise.shtml>. Acesso em: 27 de dezembro de 2017.

CLARK, Giovani. O Município em face do Direito Econômico. Belo Horizonte, MG: Del Rey, 2001.

CLARK, Giovani. Política Econômica e Estado. In: Marcelo Campos Galuppo (Org.). O Brasil que queremos: Reflexões sobre o Estado Democrático de Direito. Belo Horizonte, MG: Editora PUC Minas, 2006.

CLARK, Giovani; CORRÊA, Leonardo Alves; NASCIMENTO, Samuel Pontes do. Ideologia Constitucional e Pluralismo Produtivo. Revista da Faculdade de Direito da Universidade Federal de Minas Gerais, Número Especial: em memória do Professor Washington Peluso Albino de Souza, 2013.

GRAU, Eros Roberto. A Ordem Econômica na Constituição de 1988: interpretação e crítica. 15ª ed. São Paulo, SP: Malheiros, 2012.

OLIVEIRA, Régis Fernandes de. Curso de Direito Financeiro. $6^{a}$ ed. São Paulo, SP: Revista dos Tribunais, 2014. 
KUCINSKI, Bernardo. Cartas a Lula: o jornal particular do presidente e sua influência no governo do Brasil. Rio de Janeiro, RJ: Edições de Janeiro, 2014.

LENHARO, Mariana. Proposta de "plano de saúde popular" inclui modalidade sem internação nem urgência. G1, 08 de março de 2017. Disponível em: <http://g1.globo.com/bemestar/noticia/proposta-deplano-de-saude-popular-inclui-modalidade-sem-internacao-nemurgencia.ghtml>. Acesso em: 27 de dezembro de 2017.

MENDES, Gilmar Ferreira; COELHO Inocêncio Mártires; BRANCO, Paulo Gustavo Gonet. Curso de Direito Constitucional. $5^{a}$ ed. São Paulo, SP: Saraiva, 2010.

MIGUEL, Luis Felipe. Utopias do Pós-Socialismo: Esboços e Projetos de Reorganização Radical da Sociedade. Revista Brasileira de Ciências Sociais, Vol. 21, 61, 2006.

ROSA, Maria Berenice. Contabilidade do Setor Público. São Paulo, SP: Atlas, 2011.

SARLET, Ingo Wolfgang. A Eficácia dos Direitos Fundamentais. $8^{a}$ ed. Porto Alegre, RS: Livraria do Advogado, 2007.

SEN, Amartya. A Ideia de Justiça. Trad. Denise Bottmann e Ricardo Doninelli Mendes. São Paulo, SP: Companhia das Letras, 2011.

SOUZA, Jessé. A Ralé Brasileira: quem é e como vive. Belo Horizonte, MG: Editora UFMG, 2011.

SOUZA, Washington Peluso Albino de. Primeiras Linhas de Direito Econômico. 6 $6^{\underline{a}}$ ed. 2 $2^{\underline{a}}$ tiragem. São Paulo, SP: LTr, 2017. 
SOUZA, Washington Peluso Albino de. Direito Econômico. São Paulo, SP: Saraiva, 1980.

VIEIRA, Fabiola Sulpino; BENEVIDES, Rodrigo Pucci de Sá. Os Impactos do Novo Regime Fiscal para o Financiamento do Sistema Único de Saúde e para a Efetivação do Direito à Saúde no Brasil. Nota Técnica: IPEA, No. 28, 2016. Disponível em:

$<$ http://www.conass.org.br/wpcontent/uploads/2016/09/NOTA TECNICA IPEA241.pdf>. Acesso em: 27 de dezembro de 2017.

VIEIRA JUNIOR, Ronaldo Jorge Araujo. As Inconstitucionalidades do “Novo Regime Fiscal” Instituído pela PEC no 55, de 2016 (PEC no 241, de 2016, na Câmara dos Deputados). Boletim Legislativo do Núcleo de Estudos e Pesquisas da Consultoria Legislativa, No. 53, 2016.

Disponível em: $<$ https://www12.senado.leg.br/publicacoes/estudoslegislativos/tipos-de-estudos/boletins-legislativos/bol53>. Acesso em: 27 de dezembro de 2017.

VILAR, Isabela. Imposto sobre lucros e dividendos geraria $\mathrm{R} \$ 43 \mathrm{bi}$ ao ano, diz estudo. Senado Notícias, 14 de setembro de 2015. Disponível em: $<$ http://www12.senado.leg.br/noticias/materias/2015/09/14/impostosobre-lucros-e-dividendos-geraria-r-43-bi-ao-ano-diz-estudo $>$. Acesso em: 27 de dezembro de 2017.

A Emenda Constitucional no 95/2016 e a Violação da Ideologia Constitucionalmente Adotada The Constitutional Amendment No. 95/2016 and the Violation of the Constitutionally Adopted Ideology Submetido em: 2017-10-20 Aceito em: 2018-01-05 